\title{
Social Media Influencers, Product Placement and Network Engagement: Using AI Image Analysis to Empirically Test Relationships
}

\author{
Rutter RN, Barnes, SJ, Roper S, Nadeau J and Lettice F. \\ Industrial Management and Data Systems, 2021 \\ https://doi.org/10.1108/IMDS-02-2021-0093
}

\begin{abstract}
Purpose - This research tests empirically the level of consumer engagement with a product via a non-brand-controlled platform. We explore how social media influencers and traditional celebrities are using products within their own social media Instagram posts and how well their perceived endorsement of that product engages their network of followers.

Design/methodology/approach - 226,881 posts on Instagram were analyzed using the Inception V3 convolutional neural network $(\mathrm{CNN})$ pre-trained on the ImageNet dataset to identify product placement within the Instagram images of 75 of the world's most important social media influencers. The data were used to empirically test the relationships between influencers, product placement, and network engagement and efficiency.

Findings - Influencers achieved higher network engagement efficiencies than celebrities, however celebrity reach was important for engagement overall. Specialty influencers, known for their 'subject' expertise, achieved better network engagement efficiency for related product categories. The highest level of engagement efficiency was achieved by beauty influencers advocating and promoting cosmetic and beauty products.
\end{abstract}

Originality - Most research to date has focused on brand-controlled social media accounts. This study focused on traditional celebrities and social media influencers and product placement within their own Instagram posts to extend understanding of the perception of endorsement and subsequent engagement with followers. We extend the theory of network effects to reflect the complexity inherent in the context of social media influencers.

Practical implications - To maximize engagement and return on investment, manufacturers, retailers and brands must ensure a close fit between the product type and category of influencer promoting a product within their social media posts.

Keywords: Social Media; Influencers; Product Placement; Artificial Intelligence; Image Analysis; Object Recognition 


\section{Introduction}

The influencer phenomenon has become so important that it has led to the development of a distinct marketing specialism. A recent report from Influencer Marketing Hub (2021) shows the influencer marketing industry is set to grow to \$13.8 Billion with the number of dedicated platforms growing by $289 \%$. Influencers can command rates of $\$ 200,000$ per endorsement and are considered a good return on that investment due to their ability to affect consumer behavior. This has led to an increase in product placement approaches, with influencers portraying a more natural product use scenario within their social media posts than traditional advertisements, encouraging purchase behavior (Jin \& Muqaddam, 2019). The power, influence and value of social media influencers, as trend setters to their followers, is in part due to the increased authenticity of these influencers, as they project a more trusted source of information than traditional advertisements (Audrezet, De Kerviler, \& Moulard, 2018). Conversely, influencers' ability to affect decision making and drive purchasing behavior hinges on the perceived genuineness of the endorsement. Influencer-brand partnerships that appear disingenuous can quickly become counterproductive (Lee \& Eastin, 2020).

Consumer engagement with products and brands has been transformed by the digital revolution and the emergence of social media platforms. Consumers are creating content for or with brands themselves on brand controlled social media accounts, which has been shown to increase the depth of relationship and in turn consumer purchase intention (Brodie, Hollebeek, Jurić, \& Ilić, 2011; Van Doorn et al., 2010). Different levels of engagement with a brand through social media have been identified: endorsement engagement where a consumer simply likes a social media post and interactive engagement when a consumer discusses the brand by commenting on the social media post (Heinonen, 2011; Muntinga, Moorman, \& Smit, 2011; Van Doorn et al., 2010). Consumers are increasingly assessing product and service quality by discussing retailers, products and brands within social media posts and with other consumers (Bowden \& Mirzaei, 2021). This engagement can significantly influence the subsequent behavior of consumers (Bowden \& Mirzaei, 2021). Interactive engagement is often linked to more positive views about a brand (Dessart, 2017; Leckie, Nyadzayo, \& Johnson, 2016), but not always, for example, in times of crisis (Nadeau, Rutter, \& Lettice, 2020).

Social media platforms have evolved to fill specific needs, from keeping up with the latest world news (on Twitter), to communicating with friends and family (on Facebook), to finding out about the latest fashion trends (on Instagram). This presents an opportunity for brands to use hyper-targeted marketing channels by collaborating with influencers whose follower base matches the brand's target audience. This is particularly true of Instagram, which has emerged as the most effective social media channel for influencer marketing (De Veirman, Cauberghe, \& Hudders, 2017; Gunawan \& Huarng, 2015). According to Jin and Muqaddam (2019), exposure to product placement on Instagram generates higher credibility and a more positive brand image than exposure to the product in other contexts. A recent report highlighted that $89 \%$ of marketers agreed influencer marketing was comparable to or better than other marketing channels, ahead of both Facebook and Twitter at $45 \%$ and 33\% respectively (Bailis, 2019). In a 2017 survey, 70\% of respondents said they were more likely to trust product information delivered through social content than through traditional advertisements (Rockwood, 2017). Other surveys show that social media networks are used to find products by $60 \%$ of users, and $85 \%$ of consumers consult at least one social media network prior to purchasing a product (Boyle 2018). Lastly, a study revealed that $45 \%$ of 
respondents said they were likely to make their purchasing decisions based on online reviews or comments made by influencers (Barker, 2017).

Most research to date has focused on brand controlled social media accounts. The level of consumer engagement with a product via a non-brand-controlled platform is less well researched; not ignoring simulations (Robles, Chica, \& Cordon, 2020). As an example, a fitness influencer, such as Anllela Sagra, may post a picture of herself with a health drink in her Instagram account. Her social media account is not controlled by the health drink brand, and therefore shows the product in a more natural usage situation. In this research, we therefore focus on how both social media influencers and traditional celebrities are using products within their own Instagram posts and how well their perceived endorsement of that product engages their followers. We use artificial intelligence image analysis technology to identify product placement within influencers' Instagram images. Although artificial intelligence analysis techniques have been used to detect features within images in previous research, they have not been used to detect the placement of products within social media images. In this research, we analyze the different categories of influencer, the types of product that they feature in the images within their social media accounts, and the subsequent level of social media engagement achieved with their social media posts.

\section{Literature Review and Theoretical Framework}

Facilitated by rapid technological advances, social media has changed how opinions are formed and communicated. Social media has democratized access to information and what previously was only available to closed communities is now easily accessible. Online communities have taken conversation, debate, and opinion exchange out into the public sphere (Cooke \& Gfk, 2009).

The digital communication platforms of social media are a challenging development for interpersonal communication theory. Opinion leaders are people that have a significant, even the greatest (Cho, Hwang, \& Lee, 2012), impact on other people's adoption of products and services. Lazarsfeld, Berelson, and Gaudet (1948) originally looked at research into the influences on the 1940 presidential election and detailed a two-step flow of communication model, the information going from media to opinion leaders and then transmitted to the wider public. Park (2013) describes how the two-step model has developed into the diffusion of innovation theory, outlining how ideas spread through the social system. The classic work of Katz (1957) clarified who could be considered an opinion leader. This broke down into "who one is" (personal dispositions), "what one knows", that is one's competence and interest in an area (domain specific), and "who one knows" (social connections). This was in an era when mass media was the only real source of information. Those with an enduring involvement with a product are much more likely to be opinion leaders (Venkatraman, 1990).

Opinion leaders now emerge on digital platforms. Social media personalities are seen as relatable, trustworthy experts and early adopters who inspire the desire for a certain lifestyle, embodied by the products and services of such a lifestyle. This ability to influence opinion has been noticed and used by manufacturers and retailers as an alternative to traditional marketing and advertising (Booth \& Matic, 2011). In the UK, $66 \%$ of all adults are active social media users (Battisby, 2021), while worldwide $54 \%$ of the global population use social media, confirming the enormous ability of social media to reach ever wider audiences. This channel can also generate engagement (Brown \& Hayes, 2008) and help companies to appear more transparent and approachable, especially when receiving endorsements from 
well-known social media users.

Social media influencer marketing is defined by Jin, Muqaddam, and Ryu (2019) as endorsement and product placement by people who have knowledge or social influence on a particular topic and Cronin (2018) describes eight categories of top influencer as: Beauty, Celebrity, Fashion, Food, Fitness, Sports, Travel and 'General' influencer. Typically, influencers receive a payment (sometimes in kind), to use a product in their Instagram post as means of raising awareness and seemingly endorsing that item.

\section{$\underline{2.1 \text { Network Effects }}$}

Network effects describe situations where value is increased with the addition of new users to the network. In their seminal paper, Katz and Shapiro (1994) describe network effects such that "the value of membership to one user is positively affected when another user joins and enlarges the network, such markets are said to exhibit "network effects," (Katz \& Shapiro, 1994, p.94). A classic example to demonstrate value creation through network effects is the telephone. Additional users joining the network generate more value from the network because it can be used by more people and becomes a priority platform for communication.

The hardware/software paradigm of network effect theory (Katz \& Shapiro, 1994) is relevant to social media as the platform itself represents the hardware of the system while the users generate content that represents the software in this dynamic. Without the software or the user generated content, the platform would have very limited value. However, the theory lacks an explanation for the value created through networks within a network. Social media platforms represent networks where each node is a user who interacts with the posts of others. However, within the broader network of the platform, distinct networks are triggered with posts that are activated through views, likes and shares by other users within a person's sphere of contacts or followers.

Network effects have been studied broadly in terms of application including product adoption (Ayers, Menachemi, Ramamonjiarivelo, Matthews, \& Brooks, 2009), product design (Parker \& Van Alstyne, 2005) and immigration (McKenzie \& Rapoport, 2007). So, there is some flexibility in the theoretical application to new situations. Concurrently, there is a large body of literature examining the effects of social networks including studies about alcohol consumption (Ardila \& Herran, 2008), sexually transmitted diseases (Youm \& Laumann, 2002) and romantic relationships (Neyer \& Voigt, 2004). These studies acknowledge the powerful influence of social contacts influencing outcomes. More specifically, research about network effects has applied the theory to better understand phenomena in social media such as social media metrics (Peters, Chen, Kaplan, Ognibeni, \& Pauwels, 2013), mediated information flow (Liu, Sidhu, Beacom, \& Valente, 2017) and personal influences (Katona, Zubcsek, \& Sarvary, 2011). Peters et al. (2013) utilized network theory in part to develop guidelines for managing social media. Liu et al. (2017) explain network effects based on the integration of three other theories including the two-step flow of communication hypothesis, the theory of weak ties, and the theory of diffusion of innovations.

The theoretical basis for social media influencers appears to be quite varied. For example, influencer activity in social media has been studied under the lens of the adoption stages to better understand when influences can have an impact (Zhang, Chintagunta, \& Kalwani, 2020). Promotional rhetoric through the use of emojis to elicit consumer responses 
represents an alternative approach to understanding influencer effectiveness (Ge \& Gretzel, 2018). Kim and Kim (2021) utilize motive inference to model the effects of product and influencer congruence and sponsorship disclosure for native advertising. A counter approach to understand limits of influencer impact involves cue theory. Specifically, the cues of autonomy and influence whereby a person is interested in being perceived as carving their own path rather than following others (Valsesia, Proserpio, \& Nunes, 2020). While there is a breadth of theoretical foundations utilized in social media influencer research, these approaches provide limited understanding about the efficacy of one influencer over another. The theory of network effects can be applied to influencer networks to deepen our understanding of the efficacy of these networks.

Specific to the study of influencers in social media using network theory, Katona et al. (2011) examine network effects for influencers for the adoption of a social media platform. However, their work has been limited and there is a need to examine beyond the focus of adoption for network effects to explore the effects of specific networks within the platforms. This paper seeks to extend the theory of network effects to better understand the circulation of content among influencers' own networks within the broader platform. While metrics might include the number of unique users exposed to one's content in a social network, network effects research has yet to explore the extent of content activation beyond sheer size, which would represent a contribution to network effect theory for social media.

\subsection{Influencers and Engagement}

This research collects and analyses secondary data from the Instagram social media platform. Engagement is a key measure of social media performance. The number of social media platform followers an influencer has is the size of their audience and the level of engagement relative to their number of followers indicates engagement efficiency.

Influencers typically have a specialization which enables them to be classified by category. Object recognition is the process of identifying patterns within images and can be used to identify the categories and types of products present within an image. Table 1 summarizes the variables and measures used in the research.

Table 1: Variables and measures used in the research

\begin{tabular}{|l|l|l|l|}
\hline Acronym & Variable & Measure & References \\
\hline NU & Network Use & Frequency of posts. & (Solomon, 2017) \\
\hline NS & Network Size & Number of followers. & $\begin{array}{l}\text { (Backaler \& Shankman, 2019; } \\
\text { Katz \& Shapiro, 1994) }\end{array}$ \\
\hline NEF & $\begin{array}{l}\text { Network } \\
\text { Engagement }\end{array}$ & $\begin{array}{l}\text { Number of likes per image, as } \\
\text { positive contribution to the } \\
\text { network. }\end{array}$ & $\begin{array}{l}\text { (Ashley \& Tuten, 2015; De } \\
\text { Vries \& Carlson, 2014; IMH, } \\
\text { 2021; Van Doorn et al., 2010) }\end{array}$ \\
\hline NC & $\begin{array}{l}\text { Network } \\
\text { Category }\end{array}$ & $\begin{array}{l}\text { Relative network } \\
\text { engagement to network size }\end{array}$ & $\begin{array}{l}\text { (Breves, Liebers, Abt, \& } \\
\text { Kunze, 2019; Vaughan, 2016) }\end{array}$ \\
\hline PT & Product Type & $\begin{array}{l}\text { Product identified (using } \\
\text { object recognition software.) }\end{array}$ & $\begin{array}{l}\text { (Cronin, 2018; Schouten, } \\
\text { Janssen, \& Verspaget, 2019) }\end{array}$ \\
\hline PC & $\begin{array}{l}\text { Product } \\
\text { Category }\end{array}$ & $\begin{array}{l}\text { Category of object identified } \\
\text { (used for netwongen, Ganjtabesh, } \\
\text { fit.) }\end{array}$ & $\begin{array}{l}\text { (Breves et al., 2019; } \\
\text { Vaughan, 2016) }\end{array}$ \\
\hline
\end{tabular}

Dolan, Conduit, Fahy, and Goodman (2016) created the Social Media Engagement Behaviour (SMEB) construct, which categorises seven distinctive types of engagement behaviour which consumers demonstrate via social media platforms as: co-creation, positive 
contribution (Van Doorn et al., 2010), consumption, dormancy, detachment, negative contribution and co-destruction. Social media allows for engagement with influencers, typically in the form of 'likes' or 'comments'. By placing a product in a post, influencers are effectively endorsing that product. A like is a way for the audience to show reciprocal endorsement as SMEB 'positive contribution' to the network.

Backaler and Shankman (2019) explain that influence is dependent on the ability of social media influencers to attract many followers, providing the largest audience possible for their messages to reach. From a network effects theory perspective, the size of the network is argued to directly influence the demand for the network (Katz \& Shapiro, 1994), as shown in Figure 1.

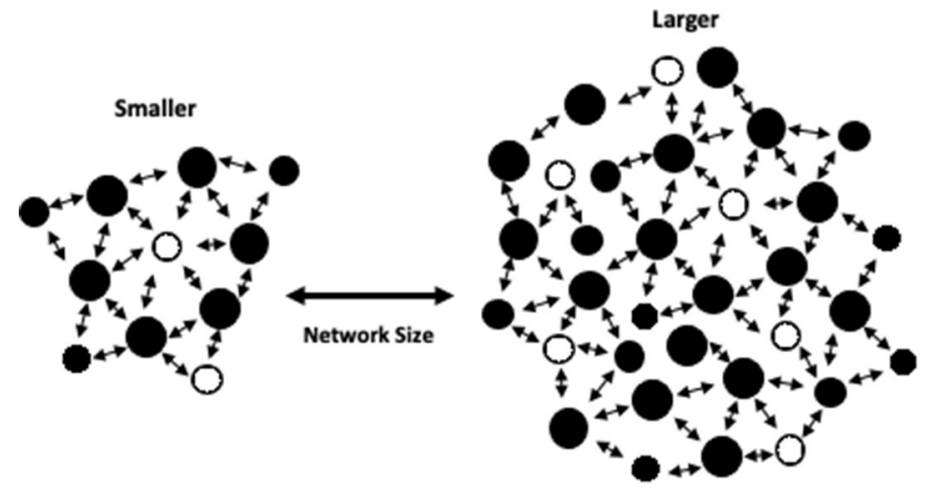

Figure 1: Reach and engagement potential for social media influencers

A large audience can be particularly attractive to the producers of mass-market products to raise product and brand awareness and measure a level of reciprocation from that influencer's audience as engagement likes. Therefore, our first hypothesis is:

H1: NS (network size, as number of followers) will be positively and significantly related to NE (network engagement, as number of likes.)

The theory of network effects suggests that the use of the network increases the value of the platform to all users. However, certain influencers are likely to be more attractive to marketers and will post product placement images more regularly than others, as shown in Figure 2.

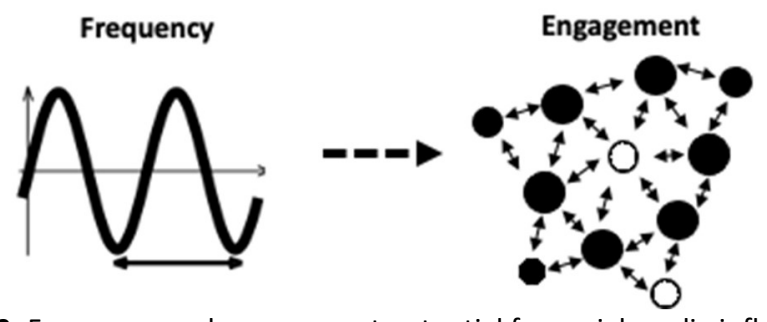

Figure 2: Frequency and engagement potential for social media influencers

Within traditional media, Solomon (2017) suggests an optimal level of frequency for exposure to gain audience attention and to aid recall; and over exposure to the same brand may reduce attention paid over-time. Given that social media influencers are posting photos of different products and brands constantly, it may be likely that 'attention fatigue' would be 
less likely; and frequent exposure to a variety of products and brands may result in higher levels of engagement at the influencer level. Therefore, our second hypothesis tests:

H2: NU (network use, as frequency of posting) will be positively and significantly related to NE (network engagement, as number of likes.)

There is some debate as to the exact definition of an "influencer" and particularly the difference between an influencer and a professional or celebrity. Influencers can become celebrities in their own right over time. However, it is possible to identify influencers who were professionals or celebrities (for something other than merely being an influencer) before they had a significant social media presence. For example, Selena Gomez, has approximately $239 \mathrm{~m}$ followers on Instagram and could be classed as a traditional celebrity, as a singer who transferred influence through television and radio to social media. Celebrities often have the largest reach, albeit potentially less targeted, therefore common products (such as household objects in natural product usage situations) often achieve more engagement than niche products that are endorsed by niche influencers.

Niche or speciality influencers have varying degrees of perceived relevance and authority, and are regarded as experts that command a level of trust with their followers in terms of experience, education and expertise (Brown \& Fiorella, 2013; Cakim, 2009; Uzunoğlu \& Kip, 2014). An influencers' level of credibility can have a significant impact on influencer endorsement effectiveness (Chapple \& Cownie, 2017; Djafarova \& Rushworth, 2017; Zhang et al., 2020). This manifests itself in opposition to the typical 'scatter gun' approach, often employed through traditional media channels. For example, fitness and sports influencers that demonstrate their fitness and skill via social media profiles are more likely to achieve engagement with sporting and health equipment. Likewise, food influencers providing photos of food and dining, linked to their recipe books, are likely to have engagement with culinary products. The product type represents a basis for a credible network within a platform where influencers can leverage their own contacts with others who interact within a topical sphere, as shown in Figure 3.

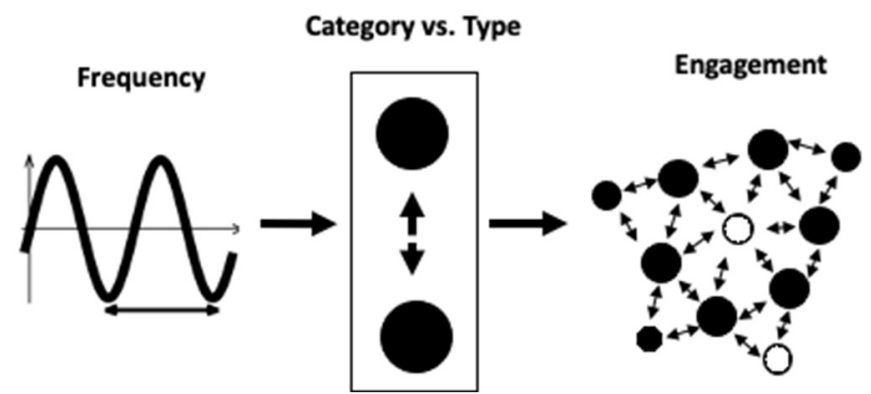

Figure 3: Frequency, level of fit and engagement potential for social media influencers

Thus, our third hypothesis concerns the relevance and authority of influencer and subsequent engagement:

H3: NU (network use) by NC (network category) will be moderated by PT (product type) and positively and significantly related to NE (network engagement.)

It may be the case that for specific product categories, greater efficiency can be achieved with a specific influencer in that area's network, in other words a greater number of likes relative to their following. Typically, influencers with a larger audience are more 
expensive, as fees are calculated based on audience size. As practitioners are concerned with efficiency of expenditure: how do influencers compare by efficiency of engagement? The next section seeks to probe these differences.

\section{$\underline{2.3 \text { Influencers and Engagement Efficiency }}$}

Quesenberry (2015) explains that it is not always the case that brands and products need to utilize 'high-profile' celebrities with a large reaching network. In fact, the opposite may be more important on social media, with increasing interest by marketers in 'general' influencers. The number of individuals falling into the 'general' category is rising, where social media influencers are famous with no specific talent - they are known, for no other reason than simply being famous (Marwick, 2015). In contrast to advertising produced by global companies, these non-corporate social media influencers are often seen as more authentic - as they post images of their 'real' daily lives. Trust is defined by Papagapitos and Riley (2009) as implicit beliefs that another party would refrain from opportunistic behavior and not take advantage of their position of influence. Schouten et al. (2019) found consumers tend to identify more with general influencers than with celebrities, as these 'normal' individuals more closely resemble themselves or their aspirational self (Shan, Chen, \& Lin, 2020; Xu \& Pratt, 2018). This closer identification with them can result in higher levels of trust within the influencer's network and an increased perceived authenticity also results in deeper trust and subsequent follower engagement.

In other words, the 'nobodies' of the past have become the 'somebodies' of the future (Booth \& Matic, 2011), spring-boarded by a digital sphere. Thus, it is likely the case that general social media influencers have greater engagement efficiency; and our fourth hypothesis concerns efficiency of engagement differences between traditional celebrities and a new breed of influencer:

H4: There will be a significant difference between traditional celebrities and influencers for NEF (network engagement efficiency.)

Furthermore, speciality influencers boast 'value for money' as efficiency in accessing a network, so it may be more efficient to use speciality influencers within a specific realm. Those social media influencers that concentrate upon specific categories of product to ensure they achieve maximum engagement can further develop their own brand. The relevance of an influencer (known as product-endorser fit) is necessary to illicit a desired response efficiently from that influencer's followers (Breves et al., 2019). Vaughan (2016) found that noncelebrity influencers (also known as speciality or category influencers) can achieve up to ten times more engagement efficiency than their celebrity peers. Conversely, brands may need to consider the category of their influencer to better assess the appropriate network within the correct platform. Thus, we posit that overall:

H5: There will be significant differences between NC (network category), PT (product type) fit and NEF (network engagement efficiency.)

Most research to date has focused on brand controlled social media accounts. This research is innovative in its focus on the level of consumer engagement with a product via a non-brand-controlled platform, showing products in more natural usage situations. In this research, we explore how both social media influencers and traditional celebrities are using products within their own social media Instagram posts and how well their perceived endorsement of that product engages their followers. In particular, we analyze the size of the 
influencers' networks and frequency of posting on engagement, the differences between different categories of influencer on engagement, and the influence of network category and product type fit on network engagement efficiency.

\section{Methodology}

Emerging technologies provide opportunities to yield valuable new insights into consumer behavior and optimize expenditure within the marketing mix (Wedel \& Kannan, 2016). Image analysis can be used to better understand the influence of social media platforms with a strong visual component (Hill, Kender, Natsev, Smith, \& Xie, 2017; Li \& Xie, 2020). Developments in computational power and artificial intelligence (AI) enable sophisticated neural networks to be trained to recognize features in an image. These features range from facial recognition techniques to analyze a human face (Bougourzi, Dornaika, Mokrani, Taleb-Ahmed, \& Ruichek, 2020) and determine a consumer's age and even their sentiment (Barnes \& Rutter, 2019), to the brand of a car (Wedel \& Kannan, 2016), to the type of object being held (Kheradpisheh et al., 2018) or indeed to predict product purchase (Kim, Lee, Jeon, \& Song, 2020).

This research is innovative in its use of artificial intelligence to detect product placement within influencers' Instagram images, which is described in more detail in section 3.3, and to use that data to empirically test the relationships between social media influencers, product placement, and engagement and efficiency. The research process is summarized in Figure 4.

Figure 4: Summary of research process

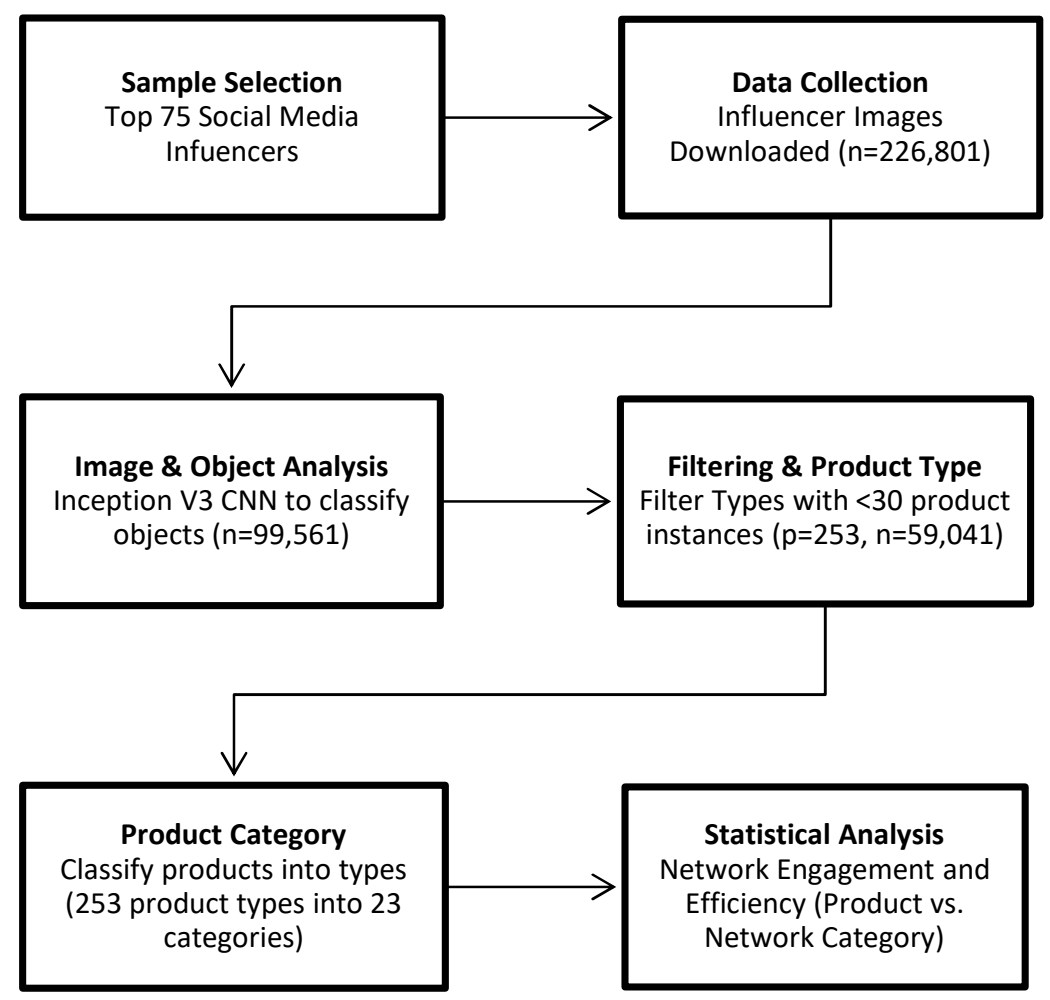

\section{$\underline{\text { 3.1. Sample Selection }}$}

Social media is a global phenomenon and has global influencers. To provide a range of global influencers and an adequate variation in their performance, the top 75 social media 
influencers from the "Instagram Rich List" were selected as the sample for this research. This list provides influencer earning power from product placement and brand alliances, meaning that the influencers included are likely to be endorsing products in exchange for money. The top 75 influencers have between 1 million and 110 million followers and come from around the world, with a combined total follower count of 1.85 billion and a mean of 24.7 million followers. The sample includes 8 categories based on Schouten et al. (2019)'s previous work and the top 75 influencers charging the most per sponsored post within a niche to represent the largest variance in marketing budgets between niches of influencer. These categories are: Beauty, Celebrity, Fashion, Food, Fitness, General Influencer, Sports and Travel. Some of the influencers are in multiple categories. Table 2 shows these influencers by network category and size.

The approach is unique as it categorizes influencers based on their market value and relative earnings. Celebrity Influencers who are also paid to endorse Sports products are included in both the Celebrity and Sports categories, as deals with sporting celebrities are often part of a larger endorsement campaign. For example, Cristiano Ronaldo is a Celebrity Influencer for a range of general product endorsements (underwear, aftershave) as well as for Sports related products (trainers, sports equipment), whilst Lionel Messi is only included as a paid influencer for the Sports category, based on market earnings. The cost per 1,000 followers varied between categories. Celebrity Influencers had the highest average cost per 1,000 followers and Food Influencers had the lowest.

Table 2: Edited 75 top social media influencers based on earnings from brands

\begin{tabular}{|c|c|c|c|}
\hline No & Name & Network Category & Network Size \\
\hline 1 & Kylie Jenner & Celebrity & $110,000,000$ \\
\hline 2 & Selena Gomez & Celebrity & $138,000,000$ \\
\hline 3 & Cristiano Ronaldo & Celebrity, Sports & $133,000,000$ \\
\hline 4 & Kim Kardashian & Celebrity & $113,000,000$ \\
\hline 5 & Beyonce Knowles & Celebrity & $115,000,000$ \\
\hline 6 & Dwayne Johnson & Celebrity & $109,000,000$ \\
\hline 7 & Justin Bieber & Celebrity & $100,000,000$ \\
\hline 8 & $\begin{array}{l}\text { Neymar da Silva Santos } \\
\text { Junior }\end{array}$ & Celebrity, Sports & $101,000,000$ \\
\hline 9 & Lionel Messi & Sports & $95,300,000$ \\
\hline 10 & Kendall Jenner & Celebrity & $92,400,000$ \\
\hline 30 & Jen Selter & Fitness & $12,200,000$ \\
\hline 31 & Ana Cheri & Fitness & $11,200,000$ \\
\hline 32 & Felix Kjellberg & General & $14,200,000$ \\
\hline 33 & Logan Paul & General & $16,300,000$ \\
\hline 34 & Gianluca Vacchi & Fashion & $11,500,000$ \\
\hline 35 & Anllela Sagra & Fitness & $10,500,000$ \\
\hline 50 & Amra Olevic & Beauty & $5,500,000$ \\
\hline 51 & Chris Burkard & Travel & $3,000,000$ \\
\hline 52 & Frederico Lucia & Fashion & $5,800,000$ \\
\hline 53 & Jack Morris & Travel & $2,800,000$ \\
\hline 54 & Ulisses Jr & Fitness & $5,100,000$ \\
\hline 55 & Jamie Oliver & Food & $6,400,000$ \\
\hline 70 & Joe Wicks & Food & $2,100,000$ \\
\hline 71 & Martha Stewart & Food & $1,800,000$ \\
\hline 72 & Cezar Gonzalez & Food & $1,800,000$ \\
\hline 73 & Ella Mills & Food & $1,300,000$ \\
\hline 74 & Kevin Curry & Food & $1,200,000$ \\
\hline \multirow[t]{4}{*}{75} & David Chang & Food & $1,000,000$ \\
\hline & & Total & $1,851,100,000$ \\
\hline & & Mean & $24,681,333$ \\
\hline & & Std. dev. & $36,358,648$ \\
\hline
\end{tabular}




\subsection{Data Collection}

The Instagram images posted over a 12-month period by the accounts of the top 75 influencers were collected, using a process of spidering (using the Instagram API in conjunction with Python). The process took seven days and resulted in 226,801 post images. Key fields extracted for subsequent analysis are shown in Table 3.

Table 3: Product categories

\begin{tabular}{|l|l|}
\hline Key Field & Metadata \\
\hline ID & Unique identification number of the post. \\
\hline Shortcode & URL shortcode for the post. \\
\hline Likes & Number of likes for the post. \\
\hline Image & The image data of the post. \\
\hline
\end{tabular}

\subsection{Image Analysis and Object Classification}

A combination of Python, OpenCV and Keras were used to load each image (Gollapudi, 2019) and four convolutional neural networks (CNNs) were tested on a subset of data to test reliability (MobileNetV2, ResNet50, InceptionV3, DenseNet121.) The CNNs were pre-trained on the ImageNet dataset which consists of more than a million images which can classify 1000 object categories (Krizhevsky, Sutskever, \& Hinton, 2012). Manual checks on a 30\% subset of the total influencer categories $(n=1,095,100$ predictions from each of the 7 categories) were undertaken to compare performance. InceptionV3 was slower, but consistently the most accurate and was selected for the main study.

InceptionV3 is the third iteration of the Inception family of architecture frameworks, based on the original Googlenet module (Szegedy, Vanhoucke, Ioffe, Shlens, \& Wojna, 2016). The CNN uses $7 \times 7$ convulsion layers (to pixel filter the image and produce a resulting image), pooling layers (to reduce image data and keep only the most valuable pixels, whilst reinforcing main features), label smoothing (to prevent largest logit from becoming larger than others) and auxiliary classifiers (to propagate label information lower down). Figure 5 highlights this process, with an example. 
Figure 5: InceptionV3 CNN for ImageNet and example of object detected
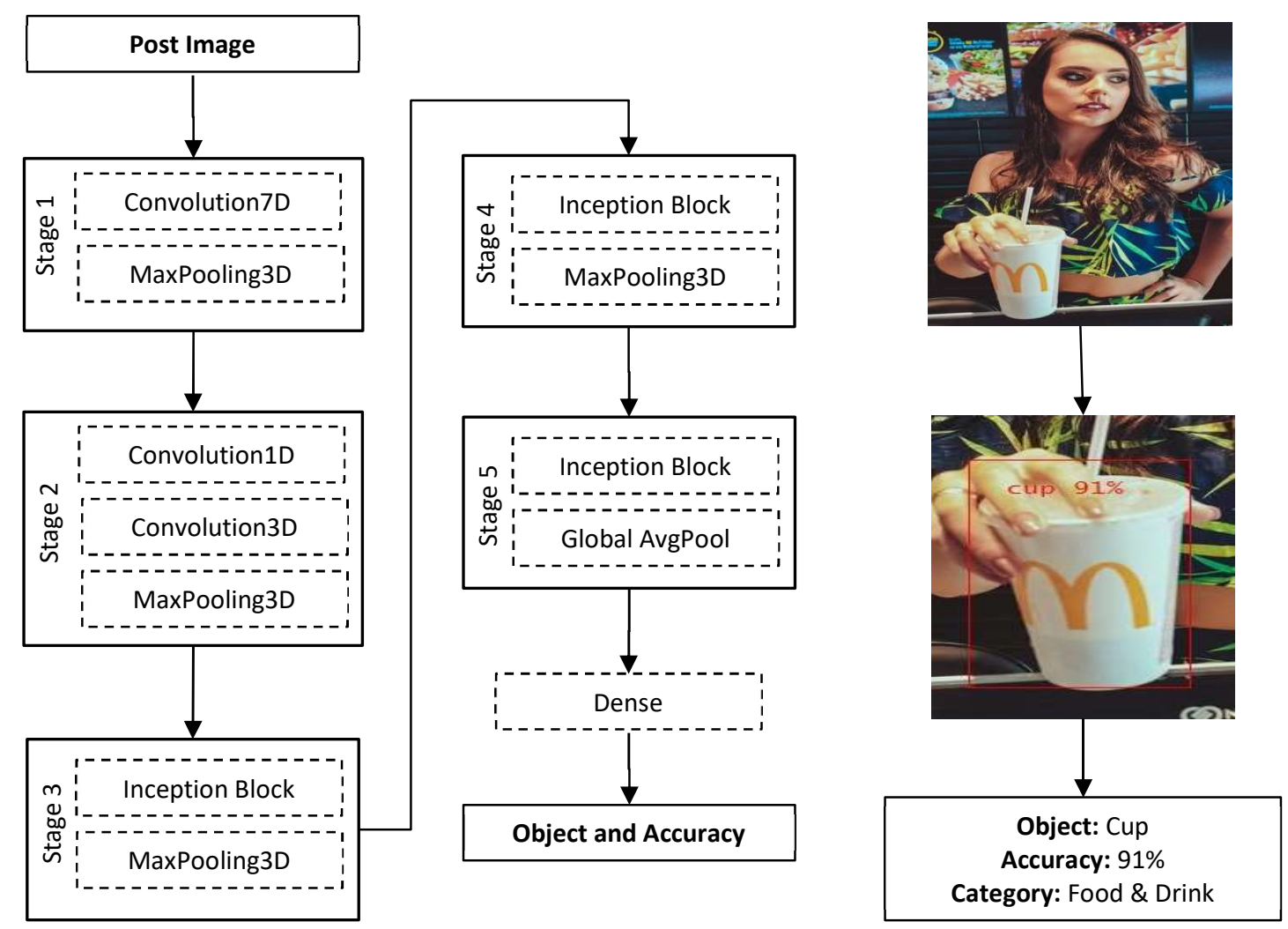

\section{$\underline{3.4 \text { Scene Classification and Filtering Process }}$}

The process described was used for classification on the entire sample $(n=226,801)$ images and took approximately 3 days. Chen and Matsumaru (2019) explain that object recognition can be particularly difficult when a portion of the object is outside of the image or positioned at an uncommon angle; and found that Inception V3 can achieve $80 \%$ accuracy when only $45 \%$ of the object in the image is visible (and $86 \%$ accuracy when the overlapping rate is lower than 30\%.) Accuracy of object detection and subsequent categorization was fundamental for validity. Therefore, all objects were screened for above $80 \%$ prediction accuracy to focus on those images where an object existed and could be identified and categorized. This resulted in approximately one hundred thousand object containing images $(n=99,561)$. To focus on the most important product types, object type instances of less than 30 for each influencer category were then removed. This resulted in approximately sixty thousand images $(n=59,041)$ over the 75 influencers, and included 253 different products for statistical analysis.

Each product was then manually classified into category types with the assistance of the ImageNet database (ID, name and example) and a well-known online product retailer. A search was made on the retailer's website and the subsequent department category was used. This resulted in 23 categories which included all 253 products. In order to protect validity, each researcher then appraised the classification and highlighted potential discrepancies. These were then considered in further detail by reviewing product placement images to reach agreement. The 23 most popular categories are listed in Table 4 . Table 5 provides further examples. 
Table 4: Product categories

\begin{tabular}{|c|c|c|c|}
\hline 1. & Active \& Sporting Persons & 9. $\quad$ Furniture & 17. Sports \& Health Equipment \\
\hline 2. & Animals & 10. Geology \& Environment & 18. Stores \& Businesses \\
\hline 3. & Books \& Stationery & 11. Kitchen \& Dining & 19. Technology \\
\hline 4. & Buildings \& Structures & 12. Medical Objects & 20. Toys \& Games \\
\hline 5. & Clothing \& Accessories & 13. Misc. Outdoor Objects & 21. Travel \& Outdoor Items \\
\hline 6. & Cosmetics \& Beauty & 14. Household Objects & 22. Vehicles \\
\hline 7. & Entertainment Related & 15. Misc. Objects & 23. Wedding \& Relationships \\
\hline 8. & Food \& Drink & 16. Musical Instruments & \\
\hline
\end{tabular}

\subsection{Coding for Statistical Analysis}

Based on Djafarova and Rushworth (2017)'s work on endorser relevance, the influencer categories and product categories for the remaining data were organized for "fit" to test the final hypothesis, as shown in Table 5. Based on Schouten et al. (2019)'s study, celebrities were separated from influencers and matched with general product categories and types of product. Then, Fashion, Food and Travel Influencers were matched with product categories and types associated with each of those influencer categories. Beauty Influencers were matched with Cosmetic \& Beauty and Medical Object product categories and types. Finally, Sports and Fitness Influencers were matched to the same Active \& Sporting Persons and Sports \& Health Equipment product categories and types to test differences between similar types of Influencers.

Table 5: Influencer category, fit, product categories and product types

\begin{tabular}{|c|c|c|}
\hline $\begin{array}{l}\text { Network } \\
\text { Category }\end{array}$ & Product Categories & Product Types Examples \\
\hline Celebrity & $\begin{array}{l}\text { [A] Entertainment-Related; [B] } \\
\text { Household Objects; [C] } \\
\text { Miscellaneous Objects; [D] } \\
\text { Musical Instruments; [E] } \\
\text { Technology; [F] Toys \& Games, } \\
\text { [G] Vehicles; [H] Weddings \& } \\
\text { Relationships }\end{array}$ & $\begin{array}{l}\text { [A] Microphone, Spotlights, Stage, Television; [B] } \\
\text { Bath Towel, Hot tub, Candle, Vase; [C] Christmas } \\
\text { Stocking, Nappy; [D] Accordion, Harmonica, Oboe, } \\
\text { Saxophone, Violin; [E] Mobile Phone; [F] Balloon, } \\
\text { Jigsaw, Teddy; [G] Bicycle, Jeep, Limousine, } \\
\text { Motorbike; [H] Altar, Bride, Groom }\end{array}$ \\
\hline Fashion & $\begin{array}{l}\text { A] Clothing \& Accessories [B] } \\
\text { Furniture; [C] Stores \& Business }\end{array}$ & $\begin{array}{l}\text { [A] Bikini, Jeans, Miniskirt, Purse, Suit, Sunglasses, } \\
\text { Swimming Trunks; [B] Dining Table, Couch, Chair; }[\mathrm{C}] \\
\text { Barber Shop, Grocery Store, Shoe Store }\end{array}$ \\
\hline Travel & $\begin{array}{l}\text { [A] Animals; [B] Buildings \& } \\
\text { Structures; [C] Geology \& } \\
\text { Environment; [D] Travel \& } \\
\text { Outdoor Items }\end{array}$ & $\begin{array}{l}\text { [A] Bear, Camel, Crayfish, Shark, Penguin, Whale; [B] } \\
\text { Boathouse, Bridge, Castle, Dam, Palace, Pier; [C] } \\
\text { Beach, Cliff, Lakeside, Mountain; [D] Binoculars, } \\
\text { Tent, Sun Cream }\end{array}$ \\
\hline Food & $\begin{array}{l}\text { [A] Books \& Stationery; [B] Food } \\
\text { \& Drink; [C] Kitchen \& Dining }\end{array}$ & $\begin{array}{l}\text { [A] Book, Eraser; Pen; [B] Bagel, Broccoli, Espresso, } \\
\text { French Bread, Ice Cream, Mushrooms, Pizza, } \\
\text { Pomegranate; [C] Bowl, Frying Pan, Plate, Pot, Tray, } \\
\text { Wok }\end{array}$ \\
\hline $\begin{array}{l}\text { Fitness } \\
\text { Sports }\end{array}$ & $\begin{array}{l}\text { [A] Active \& Sporting Persons; [B] } \\
\text { Sports \& Health Equipment }\end{array}$ & $\begin{array}{l}\text { [A] Football Player, Scuba Diver; [B] Barbell, } \\
\text { Dumbbell, Horizontal Bar, Punch Bag }\end{array}$ \\
\hline Beauty & $\begin{array}{l}\text { [A] Cosmetics \& Beauty; [B] } \\
\text { Medical Objects }\end{array}$ & $\begin{array}{l}\text { [A] Face powder, Hair Spray, Hair Dryer, Lipstick, } \\
\text { Lotion, Perfume; [B] Syringe, Hospital Bed, Oxygen } \\
\text { Mask, Medical Tool }\end{array}$ \\
\hline
\end{tabular}

The Instagram post data and classification data were combined, and new metrics were calculated for network engagement and efficiency to conduct the descriptive and inferential statistical analyses. Descriptive statistics for each variable are provided in Table 6. For network engagement, Medical Objects has the highest and Miscellaneous Outdoor Objects has the lowest engagement efficiency. For network engagement efficiency, Weddings \& Relationships has the highest and Books \& Stationery has the lowest average efficiency. 
Table 6: Descriptive statistics

\begin{tabular}{|l|l|l|}
\hline Variable & Mean & St. Dev \\
\hline Network Engagement & $226,151.18$ & $593,272.54$ \\
\hline Network Size & $21,262,095.83$ & $33,179,430.10$ \\
\hline Network Engagement Efficiency & 0.01112 & 0.01665 \\
\hline
\end{tabular}

\section{Analysis and Findings}

This section begins by analyzing the relationship between (4.1) the number of followers (network size) and engagement; (4.2) frequency of product placement image (network use) and engagement; (4.3) frequency of product placement image and influencer vs product type; and (4.4) the difference between influencer efficiency and the difference moderated by influencer vs. product type fit. The hypotheses are summarized in section 4.5.

The data were tested for statistical assumptions for each section to confirm data were suitable for appropriate analysis (Field, 2009). During this process, scatter plots were generated between key independent variables and the dependent variable. Visually, nearly all key independent variables appear positively correlated to engagement.

\section{$\underline{4.1 \text { Influencers and Engagement }}$}

Linear regression was calculated, and Network Size (number of followers) positively and significantly predicts Network Engagement $(\beta=.626, p<.001)$ and explains an important proportion of variance, $R^{2}=.39$. Hypothesis $H 1$ is therefore supported. This reinforces the foundational assertion of network effects theory where a larger network has greater effects through an increased demand for the network (Katz \& Shapiro, 1994). In this case, a larger number of followers results in higher levels of engagement performance. The relationship is highlighted in Figure 6.

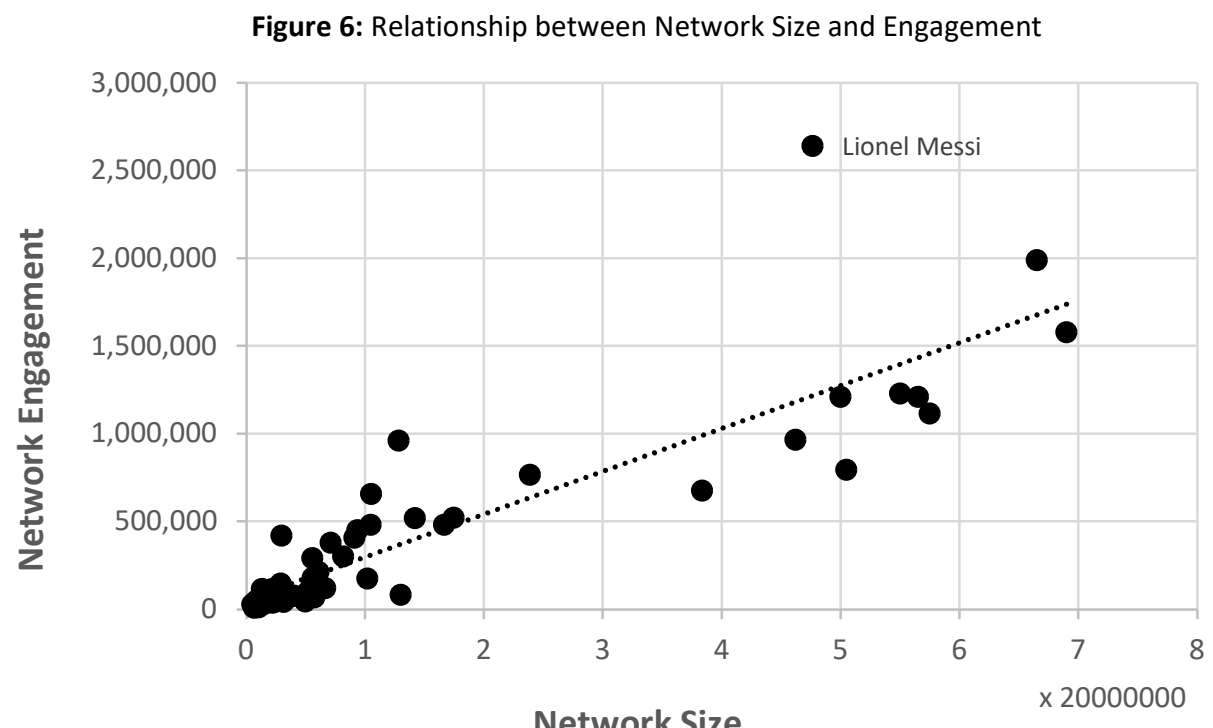

\section{$\underline{4.2 \text { Frequency and Engagement }}$}

Regression was conducted to test Hypotheses H2 and H3. Network Use (the frequency of product placement posts) did significantly predict Network Engagement ( $\beta=$ $.626, p<.001$ ) and explain a small proportion of variance, $R^{2}=.06$. However, the relationship was negative. Hypothesis $\mathrm{H} 2$ is therefore rejected. While network effects would be expected 
in networks that are used more frequently, the law of diminishing returns appears relevant, as more posts did not seem to help engagement, indeed the relationship was more complex. However, it did appear that some influencers were better at converting followers into likes, or some followers were more difficult to convert. Figure 7 highlights the relationship.

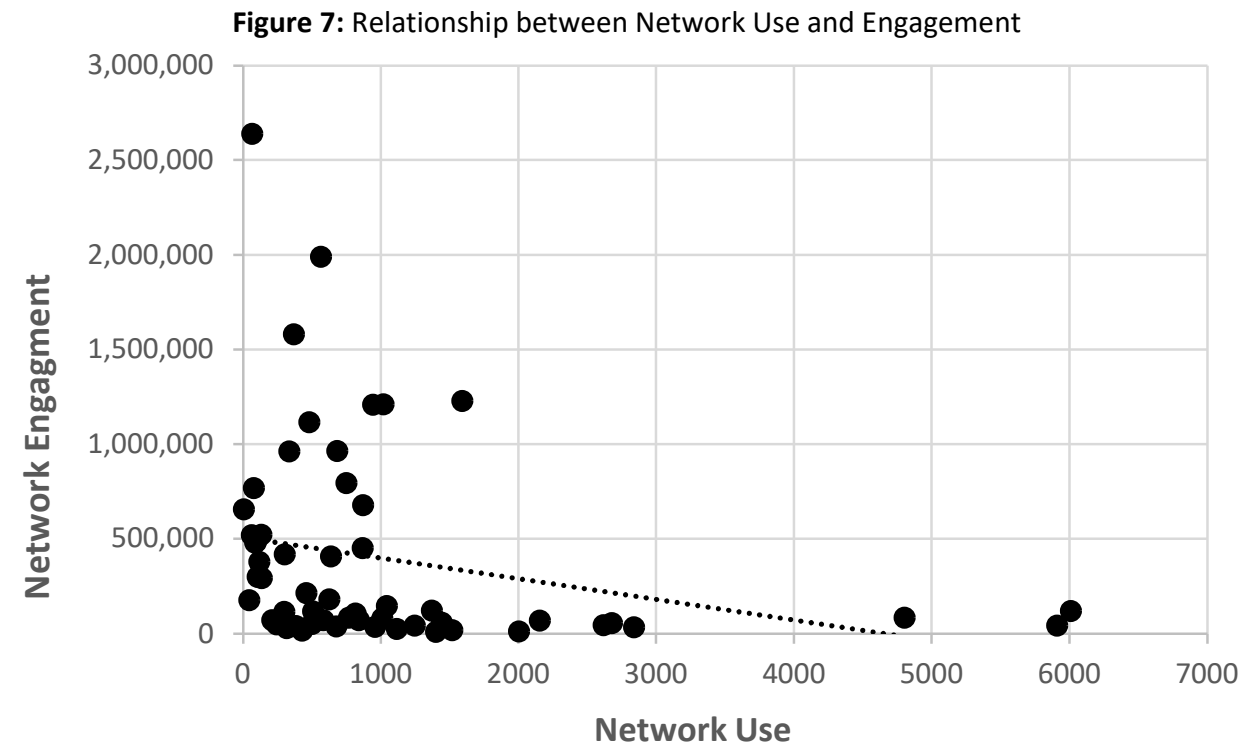

\section{$\underline{4.3 \text { Frequency, Type and Engagement }}$}

The interactions were entered in the second step of a hierarchical regression analysis. In the final step, the interaction term is entered (that is the product of the two variables Influencer Category x Product Type) and explains a significant increase in variance in Engagement, $R^{2}=.82(p<.001)$. Hypothesis H3 is therefore fully supported as all influencers' posts (NU) and subsequent engagement (NE) were moderated by product category (PC). Table 7 highlights the significant relationships. It can be interpreted as follows: H3[a] Beauty Influencers were able to promote a larger range of products more frequently; however, they were penalized when posting more technology and vehicle photos. This is perhaps symptomatic of the Instagram platform being more focused on photogenic beauty. Based on this finding, the network effects appear to be greater when the influencer is situated within the appropriate context and can be viewed as a credible source (Chapple \& Cownie, 2017; Djafarova \& Rushworth, 2017).

Table 7: Influencer and product type which results in significantly higher engagement

\begin{tabular}{|l|l|}
\hline $\begin{array}{l}\text { Network } \\
\text { Category }\end{array}$ & Product Category (No of Post vs. Change in Engagement) \\
\hline [a] Beauty & $\begin{array}{l}\text { Books }(\beta=.678, p<.001), \text { Clothing }(\beta=.787, p<.001), \text { Cosmetics }(\beta=1.015, \\
p<.005), \text { Entertainment }(\beta=.598, p<.05), \text { Food and Drink }(\beta=.480, p< \\
.05), \text { Medical }(\beta=.790, p<.05), \text { Technology }(\beta=-.487, p<.05), \text { Vehicles }(\beta= \\
-.793, p<.005)\end{array}$ \\
\hline [b] Celebrity & Books $(\beta=.632, p<.001)$, Technology $(\beta=-1.141, p<.001)$ \\
\hline [c] Fashion & $\begin{array}{l}\text { Books }(\beta=.587 p<.001), \text { Buildings }(\beta=.548, p<.01), \text { Clothing }(\beta=.501, p< \\
.005), \text { Cosmetics }(\beta=.501, p<.01), \text { Geology }(\beta=.434, p<.05), \text { Medical }(\beta= \\
\text {.405, } p<.001)\end{array}$ \\
\hline [d] Food & $\begin{array}{l}\text { Clothing }(\beta=-.489, p<.05), \text { Household Objects }(\beta=.405, p<.01), \text { Sports } \\
(\beta=.674, p<.05), \text { Technology }(\beta=-1.114, p<.001)\end{array}$ \\
\hline [e] Fitness & $\begin{array}{l}\text { Books }(\beta=1.291, p<.001), \text { Clothing }(\beta=.625, p<.05), \text { Cosmetics }(\beta=.776, \\
p<.01), \text { Food and Drink }(\beta=.879, p<.001), \text { Geology }(\beta=.947, p<.001)\end{array}$ \\
\hline
\end{tabular}




\begin{tabular}{|l|l|}
\hline [f] General & $\begin{array}{l}\text { Books }(\beta=1.149, p<.001), \text { Beauty }(\beta=1.015, p<.001), \text { Clothing }(\beta=.462, p \\
<.001), \text { Food and Drink }(\beta=.480, p<.05), \text { Geology and Landscapes }(\beta= \\
.947, p<.001), \text { Medical }(\beta=.790, p<.005)\end{array}$ \\
\hline [g] Sports & Technology $(\beta=-1.141, p<.001)$ \\
\hline$[\mathrm{h}]$ Travel & Buildings $(\beta=.548, p<.01)$ \\
\hline
\end{tabular}

Whilst it appears the product being endorsed and influencer fit did affect the relationship between the number of posts and engagement, marketers are interested in achieving optimum engagement efficiency.

\subsection{Influencers and Engagement Efficiency}

ANOVA was conducted to test the significance of the difference between all NCs (Network Categories). Table 8 summarizes the significantly different subgroups from Tamhane's T2 post-hoc analysis, where A is the highest engagement efficiency group. General Influencers had significantly higher levels of mean network engagement $(M=0.0306)$ than Celebrities, but also Specialty Influencers (means ranged from 0.0221 for Travel Influencers to 0.0032 for general Beauty Influencers) for Network Engagement Efficiency. Hypothesis $\mathrm{H} 4$ is therefore supported, as differences were observed across all groups. In other words, over all products, more engagement per follower could be achieved using General and Speciality Influencers, rather than a traditional celebrity. Taken with the previous hypotheses, this means that whilst celebrities could achieve more engagement, it was not as efficient. So, the network effects are more efficient for influencers reflecting the relatability of the source (Schouten et al., 2019) and their network overall.

Table 8. Summary of post-hoc tests for likes by influencer category

\begin{tabular}{|l|l|l|l|l|l|l|l|l|l|l|}
\hline Network Category & Mean & \multicolumn{6}{|l|}{ Groups } \\
\hline General & 0.03060 & A & & & & & & & & \\
\hline Travel & 0.02208 & & B & & & & & & \\
\hline Sports & 0.01769 & & & C & & & & & \\
\hline Beauty & 0.01741 & & & C & & & & & \\
\hline Fashion & 0.01170 & & & & D & & & & \\
\hline Celebrity & 0.01071 & & & & & E & & & \\
\hline Fitness & 0.00771 & & & & & & F & & \\
\hline Food & 0.00707 & & & & & & & G & \\
\hline $\begin{array}{l}\text { Note: Letters indicate homogenous subsets using Tamhane's T2 (due to } \\
\text { heteroscedasticity), where A is the highest. }\end{array}$ \\
\hline
\end{tabular}

Finally, to test the differences between Network Category (NC) vs. Product Category (PC) and Network Engagement Efficiency (NEF), the efficiency for each PC and NC was calculated, and an ANOVA was used to test for significance of difference in NEF. Post-hoc multiple comparison determines which means were different using Tamhane's T2 test (due to heteroscedasticity), shown in Table 9. The letters indicate homogenous subsets, where A is the highest subgroup.

Table 9. Summary of post-hoc tests for likes by influencer category

\begin{tabular}{|l|c|}
\hline Network Category vs. Product Category (Fit) & Subgroup \\
\hline Celebrity Influencer $\rightarrow$ Entertainment Related & A \\
\hline Celebrity Influencer $\rightarrow$ Household Objects & B \\
\hline Celebrity Influencer $\rightarrow$ Miscellaneous Objects & A \\
\hline Celebrity Influencer $\rightarrow$ Musical Instruments & A \\
\hline Celebrity Influencer $\rightarrow$ Technology & B \\
\hline Celebrity Influencer $\rightarrow$ Toys \& Games & B \\
\hline
\end{tabular}




\begin{tabular}{|l|c|}
\hline Celebrity Influencer $\rightarrow$ Vehicles & B \\
\hline Celebrity Influencer $\rightarrow$ Weddings \& Relationships & C \\
\hline Fashion Influencer $\rightarrow$ Clothing \& Accessories & D \\
\hline Fashion Influencer $\rightarrow$ Furniture & A \\
\hline Fashion Influencer $\rightarrow$ Stores \& Businesses & B \\
\hline Travel Influencer $\rightarrow$ Animals & A \\
\hline Travel Influencer $\rightarrow$ Buildings \& Structures & A \\
\hline Travel Influencer $\rightarrow$ Geology \& Environment & A \\
\hline Travel Influencer $\rightarrow$ Travel \& Outdoor Items & A \\
\hline Food Influencer $\rightarrow$ Books \& Stationery & A \\
\hline Food Influencer $\rightarrow$ Food \& Drink & A \\
\hline Food Influencer $\rightarrow$ Kitchen \& Dining & B \\
\hline Fitness Influencer $\rightarrow$ Active \& Sporting Persons & C \\
\hline Fitness Influencer $\rightarrow$ Sports \& Health Equipment & D \\
\hline Sports Influencer $\rightarrow$ Active \& Sporting Persons & A \\
\hline Sports Influencer $\rightarrow$ Sports \& Health Equipment & A \\
\hline Beauty Influencer $\rightarrow$ Cosmetics \& Beauty & A \\
\hline Beauty Influencer $\rightarrow$ Medical Objects & A \\
\hline $\begin{array}{l}\text { Note: Letters indicate homogenous subsets using Tamhane's T2 (due to } \\
\text { heteroscedasticity), where A is the highest. }\end{array}$ \\
\hline
\end{tabular}

Hypothesis 5 was partially supported as 14 out of the 24 matched PCs were most efficient. However, NEF seemed more complex than simply "fit" alone. Celebrity Influencers were most efficient for only 3 out of 8 PCs, appearing to confirm the important difference between "total engagement" due to large followings and "engagement efficiency". Fashion Influencers were the most efficient for only 1 out of $3 \mathrm{PCs}$, in contrast to Travel and Beauty Influencers, who were most efficient for all categories, which perhaps reflects the nature of the Instagram platform. Beautiful people in exotic locations, often advocating treatments, seem more 'real' when portrayed by Beauty Influencers. Perhaps the most surprising result was the difference between Fitness and Sports Influencers, given that Sports Influencers were most efficient for both fitness categories, whilst Fitness Influencers were not. These findings are important because they suggest that NS is insufficient in describing network effects as it depends upon the source (influencer versus celebrity) (Schouten et al., 2019) and PC congruence (Kim \& Kim, 2021).

\subsection{Summary of Hypotheses}

The five hypotheses tested the relationships between social media influencers' followers, post frequency, product placement engagement and efficiency. Table 10 presents a summary of the results.

Table 10. Summary of post-hoc tests for likes by influencer category.

\begin{tabular}{|l|l|l|}
\hline No & Hypothesis & Finding \\
\hline 1 & Network Size $\rightarrow$ Network Engagement & Support \\
\hline 2 & Network Use $\rightarrow$ Network Engagement & No Support \\
\hline 3 & Influencer Fit $\rightarrow$ Network Use $\rightarrow$ Network Engagement & Support \\
\hline 4 & Influencer Type $\rightarrow$ Network Engagement Efficiency & Support \\
\hline 5 & Influencer Fit $\rightarrow$ Network Engagement Efficiency & Partial Support \\
\hline
\end{tabular}

The first hypothesis tests overall engagement, based on the number of followers an influencer has. More followers did indeed result in more engagement. The second hypothesis considered the frequency of posts for all product placements and found a significant negative 
relationship, highlighting a more complex relationship. The third hypothesis added product type frequency and found that a significant proportion in the variance in engagement could be accounted for by frequency, but also the type of products in the images, highlighting the importance of fit. The fourth hypothesis considered efficiency and found General Influencers achieved higher levels of efficiency than Celebrity Influencers or Specialist Influencers. The final hypothesis considered fit and engagement efficiency and found that celebrity reach was far less important for efficiency. Although relevance was not immaterial, other factors such as being 'real' and 'authentic' seemed more important. The implications of these findings will now be discussed in the context of the current literature.

\section{Discussion}

Despite fast-paced developments within influencer-based product placement marketing strategies, academic literature has lagged behind. Therefore, this study is innovative and examines the top 75 social media influencers and identifies the products appearing within influencers' Instagram posts to understand engagement and network efficiency. The findings of this research extend network theory of effects and the (Backaler \& Shankman, 2019) practitioner dichotomy of social media influencer selection as fit, community (reach, resonance, and relevance), authenticity and content. The theoretical basis of the network theory of effects suggests that a larger network bestows greater value to users (Katz \& Shapiro, 1994). While this is sufficient to describe the effects of a telephone network, the explanation is too parsimonious to explain the effects of the dynamic networks that exist within social media platforms. Therefore, we make a theoretical contribution by confirming the central tenet of the theory (i.e. size) as relevant in social media network engagement, but we also augment the theory in the context of social media through the additions of relevance, authenticity and advocacy as important considerations for network efficiency effects.

\subsection{Celebrity, Influencer and Reach}

Our findings provide evidence that brings some order to what at times appear to be the random selection of influencers. Celebrity endorsers tend to have larger audience networks. When only general products and reach were considered, celebrities had higher levels of engagement. Previous studies have identified 'fans' as a key driver of engagement (Lipsman, Mudd, Rich, \& Bruich, 2012), in that they are more likely to engage with their celebrity, which in turn encourages the fan's followers to join the conversation. Interestingly, overall engagement efficiency was poor, which could indicate that consumers see little value in liking general types of products and simply browse through photos instead. This does not necessarily mean marketing efforts are wasted, particularly in terms of awareness raising for the product and brand.

However, an important finding is that influencers achieved a higher level of engagement efficiency in their networks than celebrities. Celebrity endorsers have been a staple method for manufacturers, retailers, and brands to promote products, particularly to transfer favorable aspects of the celebrity's image onto the brand itself; traditional media have carried such images for a century. Typically if an influencer was famous, they would be referred to as a 'celebrity endorser' (McCracken, 1989) and many studies have identified this type of product endorsement as highly effective (Amos, Holmes, \& Strutton, 2008; Bergkvist $\&$ Zhou, 2016). However, in the social media sphere, practitioner literature and anecdotal evidence suggests that social media influencers were more influential than celebrity influencers. Our findings provide empirical evidence to support this premise, as social media 
influencers had higher engagement efficiency, although not when promoting more general product categories. So, the network effects are not based only on the size of the network, but other characteristics can explain how value is realized in smaller networks.

\subsection{Relevance, Authority, Influencer and Engagement}

Brown and Fiorella (2013) explain that the process of influencer and consumer engagement begins with the manufacturer or retailer choosing the influencer most suitable for their product or service. Schouten et al. (2019) examine the importance of the type of endorser (product fit), identification (perceived similarity and wishful identification) and credibility (trustworthiness and expertise) of influencer and advertising effectiveness, finding that fit and credibility are key factors.

Our findings suggest that the network effect of product-endorser fit was more pronounced for influencers than for celebrity endorsers (Schouten et al., 2019). Khamis, Ang, and Welling (2017) explain how specialist influencers are self-branded 'micro' celebrities, with typically smaller audiences than celebrity influencers. Cost per product placement can therefore be lower, so manufacturers and retailers are able to utilize multiple influencers and communicate to specialist influencer followers in a more targeted way (Brown \& Fiorella, 2013). Whilst engagement within their network was often similar to that of celebrities, as discussed in the previous section, engagement efficiency was higher, reflecting endorsements from a more targeted follower base. For example, travel influencers who post photos of their hotel are seen as more credible, as are fashion influencers posting photos of the retailer stores that they shop in, enabling word of mouth within their targeted communities of travelers and fashionistas. Relevance was important to assist with the endorsement being genuine. In other words, followers of specific influencers are more likely to believe what they are seeing than those following celebrities. Our findings indicate that for specific product categories, engagement with and trust in elites is down and trust in 'people like me' is up.

Food influencers were in the top subgroup for Food \& Drink engagement efficiency, as they were perceived as more authentic and as relevant experts within their network to be promoting food related products. The need for authenticity within celebrity endorsement literature is well documented and Dodd (2018) found authenticity, as a perceived level of influencer trustworthiness, was a facilitator of brand and product trust. As Chu and Kamal (2008) explain, expertise is critical in persuasion and expertise is the ability and competence to complete a specific task (Abrams, Cross, Lesser, \& Levin, 2003; Moorman, Deshpande, \& Zaltman, 1993). Fitness influencers were less efficient than sports influencers for Sports \& Health Equipment. Typically, sports influencers are seen as experts who rise to fame through a particular ability at their sport, whilst Fitness influencers are self-proclaimed gurus who rise to fame by posting self-transformation photos and do not demonstrate a depth of sporting expertise.

Previous studies have explored consumer engagement within brand controlled social media accounts (Heinonen, 2011; Muntinga et al., 2011). This study extends brand platform engagement to influencers representing the brand within their own social media networks in more natural product usage situations. Whilst there were many instances where the most efficient influencer was relevant to a product category, including Cosmetics \& Beauty (Beauty), Food \& Drink (Food), Shopping (Fashion) and Travel \& Outdoor Items (Travel), in some cases, the expected influencer was not always in the top category, e.g. Sports \& Health Equipment was lowest for fitness influencers. 


\subsection{Advocacy and Engagement}

Cakim (2009) explains that the level of influence and engagement a social media agent may achieve can be predicted by the levels of product advocacy made, the relevance of the product to the influencer and their network of followers, the total reach of the network and the authority of the influencer as an expert.

Our findings show that influencers who advocate on social media had better performance. For Cosmetics \& Beauty products, Beauty influencers had the largest engagement, and the most efficient engagement in their networks. Lipsman et al. (2012) note the value of relating to branded content and that having Beauty influencers as advocates is effective, as they provide tutorials for their followers, demonstrating how to use the products. Audrezet et al. (2018) explain that authenticity is comprised of passionate and transparent authenticity. Social media influencers who create tutorials to demonstrate how to use a product are transparent in their endorsement and passionate about benefits when advocating a product to their network of followers, irrespective of whether those followers perceive that the influencer has been paid to promote the product.

\section{Conclusions}

This research is unique in that it tests empirically and objectively the relationship between social media influencer category, product category and social media network engagement and efficiency by using AI image analysis of products placed within social media influencer Instagram posts.

\section{$\underline{6.1 . ~ M a n a g e r i a l ~ I m p l i c a t i o n s ~}$}

Our findings show that influencers were more efficient per follower for engagement than celebrities over all product categories. For general product categories, celebrity reach appeared important, so manufacturers, retailers and brands might be able to use celebrities to increase awareness and engagement for products that are not particularly exciting. Celebrities are more expensive for product placement campaigns, so greater engagement could be achieved by using more specialist influencers, especially where fit is good, and relevance is high. The study shows that relevance and authority were important for engagement and efficiency, particularly when influencers are experts in an area of relevance to the product category. A social media influencer who has both relevance and authority and is advocating purchase or use of their product category has highest engagement efficiency. Whilst further research is necessary, this could indicate that followers are engaging in a different way and perhaps clicking on that product - representing the start of the traditional marketing funnel through to a related website.

The creation of natural product use scenarios generates greater engagement than more traditional forms of advertising (Hughes, Swaminathan, \& Brooks, 2019; Russell \& Rasolofoarison, 2017). Product placement within influencers' social media posts enables a highly personalized customer-centric approach, which is starting to replace more traditional product-centric advertising strategies. To maximize engagement and return on investment, manufacturers, retailers and brands must ensure a close fit between the product type and category and the influencer promoting a product within their social media posts. The embedding of products into social media posts, where the fit is good, starts to make content and advertising virtually indistinguishable from each other. Its effectiveness ranks well, 
particularly as content consumption has become part of everyday life and as consumers are constantly checking and engaging with their social media accounts.

\subsection{Limitations and Future Research}

This paper focuses on Instagram as the methodology used relies on an image heavy platform to analyze product placements. Instagram is heavily skewed towards younger consumers; therefore, the findings of this research may not be generalizable to the entire population. For example, older consumers tend to use Facebook, Twitter, and other media differently and for different reasons. This study is reliant on social media post likes as endorsement, however, an extension to the study would be to perform sentiment analysis on the comments to gauge both positive and negative aspects of engagement. A future study could also analyze product placement in videos posted on social media platforms, including Instagram and YouTube, to understand the differences between the impact of a product placed in an image contrasted with a product placed within a video on network engagement and efficiency.

\section{References}

Abrams, L. C., Cross, R., Lesser, E., \& Levin, D. Z. (2003). Nurturing interpersonal trust in knowledge-sharing networks. Academy of Management Perspectives, 17(4), 64-77.

Amos, C., Holmes, G., \& Strutton, D. (2008). Exploring the relationship between celebrity endorser effects and advertising effectiveness: A quantitative synthesis of effect size. International Journal of Advertising, 27(2), 209-234.

Ardila, M. F., \& Herran, O. F. (2008). Expectancies towards alcohol consumption in Bucaramanga, Colombia. Revista medica de Chile, 136(1), 73-82.

Ashley, C., \& Tuten, T. (2015). Creative strategies in social media marketing: An exploratory study of branded social content and consumer engagement. Psychology \& Marketing, $32(1), 15-27$.

Audrezet, A., De Kerviler, G., \& Moulard, J. G. (2018). Authenticity under threat: When social media influencers need to go beyond self-presentation. Journal of Business Research, 117, 557-569.

Ayers, D. J., Menachemi, N., Ramamonjiarivelo, Z., Matthews, M., \& Brooks, R. G. (2009). Adoption of electronic medical records: the role of network effects. Journal of Product \& Brand Management, 18(2), 127-135.

Backaler, J., \& Shankman, P. (2019). Digital Influence: Unleash the Power of Influencer Marketing to Accelerate Your Global Business: Springer International Publishing.

Bailis, R. (2019). The State of Influencer Marketing: 10 Influencer Marketing Statistics to Inform Where You Invest. Retrieved from https://www.bigcommerce.com/blog/influencer-marketing-statistics/\#what-isinfluencer-marketing

Barker, S. (2017). How Social Media Is Influencing Purchase Decisions. Retrieved from https://socialmediaweek.org/blog/2017/05/social-media-influencing-purchasedecisions/

Barnes, S., \& Rutter, R. (2019). A Framework for Facial Image Analytics Using Deep Learning in Social Sciences Research. Paper presented at the 4th International Conference on Digital Economy, Beirut, Lebanon.

Battisby, A. (2021). The Latest UK Social Media Statistics for 2021. Retrieved from https://www.avocadosocial.com/the-uk-social-media-statistics-for-2021/

Bergkvist, L., \& Zhou, K. Q. (2016). Celebrity endorsements: a literature review and research agenda. International Journal of Advertising, 35(4), 642-663. 
Booth, N., \& Matic, J. A. (2011). Mapping and leveraging influencers in social media to shape corporate brand perceptions. Corporate Communications: An International Journal, 16(3), 184-191.

Bougourzi, F., Dornaika, F., Mokrani, K., Taleb-Ahmed, A., \& Ruichek, Y. (2020). Fusion Transformed Deep and Shallow features (FTDS) for Image-Based Facial Expression Recognition. Expert Systems with Applications, 156, 113459.

Bowden, J., \& Mirzaei, A. (2021). Consumer engagement within retail communication channels: an examination of online brand communities and digital content marketing initiatives. European Journal of Marketing, 55(5), 1411-1439.

Boyle , P. (2018). The Secret to the Future Growth of Your Ecommerce Channel: Social Commerce. Retrieved from https://www.bigcommerce.com/blog/social-commerce/

Breves, P. L., Liebers, N., Abt, M., \& Kunze, A. (2019). The Perceived Fit between Instagram Influencers and the Endorsed Brand: How Influencer-Brand Fit Affects Source Credibility and Persuasive Effectiveness. Journal of Advertising Research, $59(4), 440-454$.

Brodie, R. J., Hollebeek, L. D., Jurić, B., \& Ilić, A. (2011). Customer engagement: Conceptual domain, fundamental propositions, and implications for research. Journal of service research, 14(3), 252-271.

Brown, D., \& Fiorella, S. (2013). Influence marketing: How to create, manage, and measure brand influencers in social media marketing: Que Publishing.

Brown, D., \& Hayes, N. (2008). Influencer marketing: Routledge.

Cakim, I. M. (2009). Implementing word of mouth marketing: online strategies to identify influencers, craft stories, and draw customers: John Wiley \& Sons.

Chapple, C., \& Cownie, F. (2017). An investigation into viewers' trust in and response towards disclosed paid-for-endorsements by YouTube Lifestyle vloggers. Journal of Promotional Communications, 5(2).

Chen, Z., \& Matsumaru, T. (2019). Brand Recognition with Partial Visible Image in the Bottle Random Picking Task based on Inception V3. Paper presented at the 2019 28th IEEE International Conference on Robot and Human Interactive Communication (RO-MAN).

Cho, Y., Hwang, J., \& Lee, D. (2012). Identification of effective opinion leaders in the diffusion of technological innovation: A social network approach. Technological Forecasting and Social Change, 79(1), 97-106.

Chu, S.-C., \& Kamal, S. (2008). The effect of perceived blogger credibility and argument quality on message elaboration and brand attitudes: An exploratory study. Journal of Interactive Advertising, 8(2), 26-37.

Cooke, M., \& Gfk, N. (2009). Social media and market research: we are becoming a listening economy and, while the future of market research is bright, it will be different. International Journal of Market Research, 51(4), 550.

Cronin, N. (2018). The 2018 Instagram Rich List - Who Earns The Most From Social Media? Retrieved from https://www.hopperhq.com/blog/2018-instagram-rich-list/

De Veirman, M., Cauberghe, V., \& Hudders, L. (2017). Marketing through Instagram influencers: the impact of number of followers and product divergence on brand attitude. International Journal of Advertising, 36(5), 798-828.

De Vries, N. J., \& Carlson, J. (2014). Examining the drivers and brand performance implications of customer engagement with brands in the social media environment. Journal of Brand Management, 21(6), 495-515.

Dessart, L. J. J. o. M. M. (2017). Social media engagement: a model of antecedents and relational outcomes. 33(5-6), 375-399. 
Djafarova, E., \& Rushworth, C. (2017). Exploring the credibility of online celebrities' Instagram profiles in influencing the purchase decisions of young female users. Computers in Human Behavior, 68, 1-7.

Dodd, L. (2018). An analysis of the nature and role of social influencer trustworthiness within the health and fitness sector and how it facilitates brand trust. Journal of Promotional Communications, 6(2).

Dolan, R., Conduit, J., Fahy, J., \& Goodman, S. (2016). Social media engagement behaviour: a uses and gratifications perspective. Journal of Strategic Marketing, 24(3-4), 261277.

Field, A. P. (2009). Discovering statistics using SPSS: SAGE publications Ltd.

Ge, J., \& Gretzel, U. (2018). Emoji rhetoric: a social media influencer perspective. Journal of Marketing Management, 34(15-16), 1272-1295.

Gollapudi, S. (2019). Learn Computer Vision Using OpenCV: With Deep Learning CNNs and RNNs: Apress.

Gunawan, D. D., \& Huarng, K.-H. (2015). Viral effects of social network and media on consumers' purchase intention. Journal of Business Research, 68(11), 2237-2241.

Heinonen, K. (2011). Consumer activity in social media: Managerial approaches to consumers' social media behavior. Journal of Consumer Behaviour, 10(6), 356-364.

Hill, M. L., Kender, J. R., Natsev, A. I., Smith, J. R., \& Xie, L. (2017). Visual meme tracking for social media analysis. In: Google Patents.

Hughes, C., Swaminathan, V., \& Brooks, G. (2019). Driving Brand Engagement Through Online Social Influencers: An Empirical Investigation of Sponsored Blogging Campaigns. Journal of marketing, 83(5), 78-96.

IMH. (2021). Influencer Marketing Hub. Retrieved from https://influencermarketinghub.com/influencer-marketing-benchmark-report-2021/

Jin, S. V., \& Muqaddam, A. (2019). Product placement 2.0:“Do Brands Need Influencers, or Do Influencers Need Brands?”. Journal of Brand Management(26), 522-537.

Jin, S. V., Muqaddam, A., \& Ryu, E. (2019). Instafamous and social media influencer marketing. Marketing Intelligence \& Planning, 37(5), 567-579.

Katona, Z., Zubcsek, P. P., \& Sarvary, M. (2011). Network effects and personal influences: The diffusion of an online social network. Journal of marketing research, 48(3), 425443.

Katz, E. (1957). The two-step flow of communication: An up-to-date report on an hypothesis. Public opinion quarterly, 21(1), 61-78.

Katz, M., \& Shapiro, C. (1994). Systems competition and network effects. Journal of economic perspectives, 8(2), 93-115.

Khamis, S., Ang, L., \& Welling, R. J. C. S. (2017). Self-branding,'micro-celebrity'and the rise of Social Media Influencers. 8(2), 191-208.

Kheradpisheh, S. R., Ganjtabesh, M., Thorpe, S. J., \& Masquelier, T. (2018). STDP-based spiking deep convolutional neural networks for object recognition. Neural Networks, 99, 56-67.

Kim, D. H., Lee, S., Jeon, J., \& Song, B. C. (2020). Real-time purchase behavior recognition system based on deep learning-based object detection and tracking for an unmanned product cabinet. Expert Systems with Applications, 143, 113063.

Kim, D. Y., \& Kim, H.-Y. (2021). Influencer advertising on social media: The multiple inference model on influencer-product congruence and sponsorship disclosure. Journal of Business Research, 130, 405-415.

Krizhevsky, A., Sutskever, I., \& Hinton, G. E. (2012). Imagenet classification with deep convolutional neural networks. Paper presented at the Advances in neural information processing systems. 
Lazarsfeld, P. F., Berelson, B., \& Gaudet, H. (1948). The People's Choice: How the Voter Makes Up His Mind in a Presidential Campaign: Columbia University Press.

Leckie, C., Nyadzayo, M., \& Johnson, L. (2016). Antecedents of consumer brand engagement and brand loyalty. Journal of Marketing Management, 32(5-6), 558-578.

Lee, J. A., \& Eastin, M. S. (2020). I like what she's\# endorsing: The impact of female social media influencers' perceived sincerity, consumer envy, and product type. Journal of Interactive Advertising, 20(1), 76-91.

Li, Y., \& Xie, Y. (2020). Is a picture worth a thousand words? An empirical study of image content and social media engagement. Journal of marketing research, 57(1), 1-19.

Lipsman, A., Mudd, G., Rich, M., \& Bruich, S. J. J. o. A. r. (2012). The power of "like": How brands reach (and influence) fans through social-media marketing. 52(1), 40-52.

Liu, W., Sidhu, A., Beacom, A. M., \& Valente, T. W. (2017). Social network theory. The international encyclopedia of media effects, 1-12.

Marwick, A. E. (2015). Instafame: Luxury selfies in the attention economy. Public culture, 27(1), 137-160.

McCracken, G. (1989). Who is the celebrity endorser? Cultural foundations of the endorsement process. Journal of consumer research, 16(3), 310-321.

McKenzie, D., \& Rapoport, H. (2007). Network effects and the dynamics of migration and inequality: Theory and evidence from Mexico. Journal of development Economics, 84(1), 1-24.

Moorman, C., Deshpande, R., \& Zaltman, G. (1993). Factors affecting trust in market research relationships. Journal of marketing, 57(1), 81-101.

Muntinga, D. G., Moorman, M., \& Smit, E. G. (2011). Introducing COBRAs: Exploring motivations for brand-related social media use. International Journal of Advertising, 30(1), 13-46.

Nadeau, J., Rutter, R., \& Lettice, F. (2020). Social media responses and brand personality in product and moral harm crises: why waste a good crisis? Journal of Marketing Management, 36(11-12), 1031-1054.

Neyer, F. J., \& Voigt, D. (2004). Personality and social network effects on romantic relationships: A dyadic approach. European Journal of Personality, 18(4), 279-299.

Papagapitos, A., \& Riley, R. (2009). Social trust and human capital formation. Economics Letters, 102(3), 158-160.

Park, C. S. (2013). Does Twitter motivate involvement in politics? Tweeting, opinion leadership, and political engagement. Computers in Human Behavior, 29(4), 16411648.

Parker, G. G., \& Van Alstyne, M. W. (2005). Two-sided network effects: A theory of information product design. Management Science, 51(10), 1494-1504.

Peters, K., Chen, Y., Kaplan, A. M., Ognibeni, B., \& Pauwels, K. (2013). Social media metrics-A framework and guidelines for managing social media. Journal of Interactive Marketing, 27(4), 281-298.

Quesenberry, K. A. (2015). Social media strategy: Marketing and advertising in the consumer revolution: Rowman \& Littlefield.

Robles, J. F., Chica, M., \& Cordon, O. (2020). Evolutionary multiobjective optimization to target social network influentials in viral marketing. Expert Systems with Applications, 147, 113183.

Rockwood, K. (2017). Why Spending \$1,000 on an Instagram Post Might Actually Be Worth It. Retrieved from https:/www.inc.com/magazine/201702/kate-rockwood/tip-sheet$\underline{\text { social-media-influencers.html }}$ 
Russell, C. A., \& Rasolofoarison, D. (2017). Uncovering the power of natural endorsements: a comparison with celebrity-endorsed advertising and product placements. International Journal of Advertising, 36(5), 761-778.

Schouten, A. P., Janssen, L., \& Verspaget, M. (2019). Celebrity vs. Influencer endorsements in advertising: the role of identification, credibility, and Product-Endorser fit. International Journal of Advertising, 39(2), 258-281

Shan, Y., Chen, K.-J., \& Lin, J.-S. (2020). When social media influencers endorse brands: the effects of self-influencer congruence, parasocial identification, and perceived endorser motive. International Journal of Advertising, 39(5), 590-610.

Solomon, M. R. (2017). Consumer Behavior: Buying, Having, and Being: Pearson.

Szegedy, C., Vanhoucke, V., Ioffe, S., Shlens, J., \& Wojna, Z. (2016). Rethinking the inception architecture for computer vision. Paper presented at the Proceedings of the IEEE conference on computer vision and pattern recognition.

Uzunoğlu, E., \& Kip, S. M. (2014). Brand communication through digital influencers: Leveraging blogger engagement. International Journal of Information Management, 34(5), 592-602.

Valsesia, F., Proserpio, D., \& Nunes, J. C. (2020). The positive effect of not following others on social media. Journal of marketing research, 57(6), 1152-1168.

Van Doorn, J., Lemon, K. N., Mittal, V., Nass, S., Pick, D., Pirner, P., \& Verhoef, P. C. (2010). Customer engagement behavior: Theoretical foundations and research directions. Journal of service research, 13(3), 253-266.

Vaughan, C. (2016). Influencer Marketing Update: Non-Celebrity Influencers 10 Times More Likely to Drive In-Store Purchases. Retrieved from http://collectivebias.com/blog/2016/03/influencer-marketing-update-non-celebrityinfluencers-10-times-likely-drive-store-purchases/

Venkatraman, M. P. (1990). Opinion leadership, enduring involvement and characteristics of opinion leaders: a moderating or mediating relationship? ACR North American Advances.

Wedel, M., \& Kannan, P. (2016). Marketing analytics for data-rich environments. Journal of marketing, 80(6), 97-121.

$\mathrm{Xu}, \mathrm{X} .$, \& Pratt, S. (2018). Social media influencers as endorsers to promote travel destinations: an application of self-congruence theory to the Chinese Generation Y. Journal of Travel \& Tourism Marketing, 35(7), 958-972.

Youm, Y., \& Laumann, E. O. (2002). Social network effects on the transmission of sexually transmitted diseases. Sexually transmitted diseases, 29(11), 689-697.

Zhang, W., Chintagunta, P., \& Kalwani, M. (2020). Social-Media, Influencers, and Adoption of an Eco-Friendly Product: Field Experiment Evidence from Rural China. Journal of marketing. 